\title{
DRONE VIDEO CAPTURE - A NEW METHOD IN PRECISION AGRICULTURE
}

\author{
Radko Mihajlow ${ }^{1}$, Albena Ivanova ${ }^{2}$ \\ 1 - Technical University of Varna, Dobrudhza Technological College of Dobrich, 9302, 12 Dobrotica h. e., Dobrich, Bulgaria \\ 2 - Shumen University St. Konstantin Preslavski, College of Dobrich, 9302, 12 Dobrotica h. e., Dobrich, Bulgaria \\ Corresponding author contact: rmihajlow@tu-varna.bg
}

\begin{abstract}
In June 2019, an aerial image recording was performed through the use of an RGB camera equipped drone to collect image information about the condition of an experimental wheat field at an interval of seven days three times a day. The information about the weather conditions was collected within one day (June 122019) and eight measurements were taken every hour. The study explores the index values of the following commonly accepted indices: VARIgreen and ExG observed for a period of one-month and one-day and provides a thorough analysis of the received RGB digitized information. Created, for the purposes of the study, was a regression model designed for a full factor experiment of type $2^{3}$. Carefully evaluated is also the interaction of the factors that characterize the conditions of the video and the respective conclusions were further formulated as to the influence of the factors under which the observations were made. Put forward is a recommendation as regards the best time of the day to take photos and carry out video surveillance of the condition of the wheat.
\end{abstract}

Keywords: precision agriculture, quadcopter, RGB images, variety wheat, weather conditions

\section{INTRODUCTION}

The use of drones to collect visual information for the condition of arable crops is one of the modern activities as part of precision agriculture. The advantages and disadvantages of this method of crop monitoring have been known (Ekielski A. et al., 2017), (Van der Wal et al., 2013) and the advantages of small drones equipped with onboard sensors over satellites have been pointed out in details (Biserkov, 2017). For complex environmental tasks, quadcopters have been the most appropriate, (Rao Mogili U. M., \& Deepak B. B. V. L, 2018). They have provided better control of takeoff, landing and piloting over rough terrain, as well as easier control at low flight speeds. In order to select a drone suitable for agriculture, data were analyzed in more than 50 literature sources. Five types of drones were shown, and for the most common of them (indicated in 15 sources!) - a quadcopter, specific technical features were described. It was concluded that, in precision agriculture, drones were still at an early stage of development and application, but they had a future for improvement and refinement as a technology and as an application.

The possibility of describing the texture of the captured image using the fractal mathematical apparatus was presented (Ekielski A., et al., 2017), which could be applied as a measure of uniformity in the analysis. It was shown how, with the Hearst exponent, a dimensionless measure for evaluating recurring events that are sequential over time, the digital image could be represented as a $2 \mathrm{D}$ temporary process. This was a modern and promising approach with great potential.

The technical features and configuration of the quadcopter are defined (Tores-Sanches et al. 2012) and the spatial and spectral requirements for the acquisition of images by two sensors are evaluated: a conventional video camera and a six-channel multi-spectral camera with exceptional weed discrimination ability in a sunflower field at an early plant stage for subsequent rescue treatment. The steps for preparing and using a drone with both cameras are described, as well as the importance of flight altitude, pixel size on the ground, sensor properties, and spectral image information.

The spectral properties of wheat with a vegetation fraction from $0 \%$ to $100 \%$ in the visible and nearinfrared (NIR) spectral ranges were investigated to develop a technique for remote sensing (Gitelson et 
al., 2002). It was found that for a vegetation fraction greater than $60 \%$, the information content of the reflection spectra in the visible range could only be expressed by two independent pairs of spectral bands: blue from 400 to $500 \mathrm{~nm}$, red near $670-700 \mathrm{~nm}$. It was suggested to use only the visible range of the spectrum to quantify the vegetation fraction.

The optimal segmentation scale and the most appropriate texture measures to distinguish between soil, shrubs and herbaceous vegetation using unmanned aircraft have been identified (Laliberte \& Rango, 2009). Pixel-based analysis was made for a selected pixel window based on object image analysis. The image was first segmented using the values of red, green and blue (RGB) only, and then the texture was calculated. The concept of analysis by means of the "decision tree" was applied. The results provided a clear indication that segmentation scales greater than 40 for soil, grass and shrub classifications in drone images were most appropriate. An innovative practical solution to the problem of the influence of cloud cover over the field from which to obtain photo material was proposed (Van der Wal et al., 2013). A drone-mounted radar sensor that could "see" through clouds was used, like similar Green Seeker and N-Sensor sensors. The drone could not fly at a wind speed of more than $8 \mathrm{~m} / \mathrm{s}$ and the flight time was generally between 10.00 and 14.00 during the day. The probability of receiving timely useful information from a satellite was about $20 \%$, and that of drone photos regardless of weather conditions was $45 \%$ to $70 \%$. Drones were a valuable addition to satellite surveillance.

The index must be particularly sensitive to vegetative coatings, insensitive to soil brightness, insensitive to soil color, slightly influenced by weather, environmental effects and solar geometry of illumination, as well as sensor monitoring conditions, (Jackson, 1983).

Several indices based on chromatic RGB coordinates were investigated, tested and successfully identified for weeds and also for distinguishing living plant material from soil background (Woebbeke et al., 1995). The indices included r-g, g-b, (g-b) / (r-g) and 2g-r-b. Saturation or shades of colors were also used to distinguish weeds from soil. This value, expressed by the Excess Green Index, ExG $=2 \mathrm{~g}-\mathrm{r}-\mathrm{b}$ of the green chromatic coordinate, distinguishes weeds from the soil background at 0.05 significance level better than other indices. This index worked well in both shaded and non-shaded conditions.

The purpose of the present study was to collect image information (a sufficient number of digital images) about the condition of an experimental field with six wheat varieties and to analyze through the indices: VARIgreen (Gitelson, et al., 2002) and ExG (Woebbeke, 1995), which could be calculated from images obtained with an RGB camera; to determine, through a complete factor experiment of type 23 , in what combination of natural conditions: humidity, cloudiness, intensity of the sun's rays it is advisable to monitor and document the condition of the crop.

\section{MATERIAL AND METHOD}

Drone type JD 509 Pioneer equipped with RGB camera 720P HD; 1600X1200; 1/4 inch HD Color; 5G visual angle of 1200 was used for the study; video format: PAL/NTSC; video image area $3888 \mathrm{umX} 2430 \mathrm{um}$. The subject of the survey was an experimental field in which the following wheat varieties were cultivated, numbered as follows: common wheat:1. Sladuna, 2. Pchelina, 3. Katardjina; hard wheat: 4. Malena, 5. Mirabel, 6. Melina. The cultivated wheat varieties were created at the Dobrudzha Agricultural Institute - Gen. Toshevo, (Chamurliyski, P., 2019). The experiment was based on the method of the Latin square with the sowing rate of 500 germinating seeds per square meter, and the experimental plots consisted of 5 rows with a width of $1 \mathrm{~m}$ and a path of $0.5 \mathrm{~m}$ between them. The positions, points from which the pictures were taken are shown in Fig. 1. They were 8 in number and were made from a height of $1.5 \mathrm{~m}$. The field was oriented with its longer side north-south. The coordinates of point \# 1 were: $43033.189^{`} \mathrm{~N}, 027049.939^{\circ} \mathrm{E}$. 


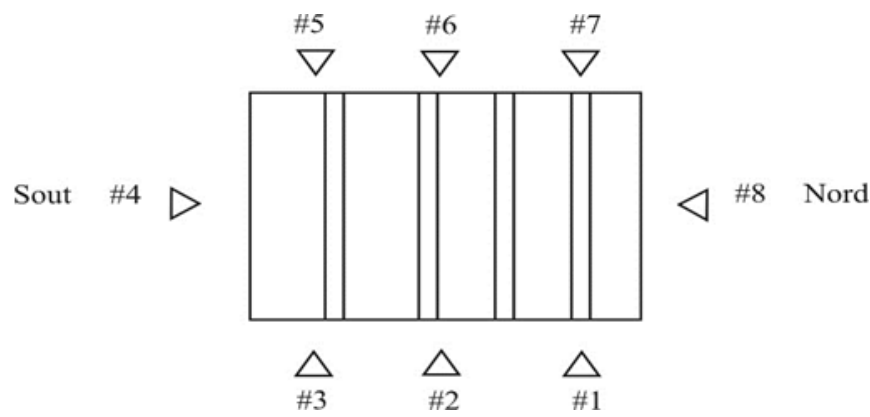

Fig. 1. Scheme of sowing and positions from which the pictures were taken

Solar radiation was measured by the instrument Solar Radiation Meter PCE-SPM1 in W/m2. In June, the images were taken at an interval of seven days three times a day. Photos were also taken within one day (12.06.2019) from 8.00 in the morning to 15.00 in the afternoon eight times using the technology FPV (First-personal Video). Digitization data for each image were obtained after uploading the image onto the MatLab software program. The program generated a multilayered array in which three of the layers corresponded to one of three colors: red, green and blue. It also provided relevant histograms.

\section{RESULTS AND DISCUSSION}

Green intensity levels were the most representative (dominant) in the distribution of brightness in each image (Rao Mogili U. M., \& Deepak B. B. V. L, 2018). The results of the measurements made between June 5 and August 24, 2019, at intervals of one week, three times a day are shown in Table 1. The values of the quantities that expressed the reflection of each of the colors for the three indexes were normalized to the maximum value by which the corresponding color from the video card on the computer was expressed. They were used to calculate vegetation indices. The charts for their change within the one-month period were constructed, (Fig. 2).

Table 1. Experimental data from one-month observation

\begin{tabular}{|c|c|c|c|c|c|c|c|}
\hline \multirow{2}{*}{ Data } & \multirow{2}{*}{ Color } & \multicolumn{3}{|c|}{ Hour } & \multirow{2}{*}{ Average values } & \multirow{2}{*}{ VARIgreen } & \multirow{2}{*}{ ExG } \\
\hline & & $\mathbf{9 , 0 0}$ & 12,00 & 15,00 & & & \\
\hline \multirow{3}{*}{ 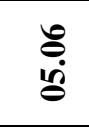 } & $\mathbf{R}$ & 106,54 & 87,19 & 88,85 & 94,19 & \multirow{3}{*}{0,0242} & \multirow{3}{*}{0,0185} \\
\hline & $\mathbf{G}$ & 95,1 & 95,96 & 98,53 & 96,53 & & \\
\hline & B & 92,55 & 87,28 & 100,84 & 93,55 & & \\
\hline \multirow{3}{*}{ 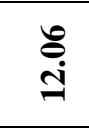 } & $\mathbf{R}$ & 110,94 & 99,12 & 92,83 & 100,96 & \multirow{3}{*}{$-0,009$} & \multirow{3}{*}{0,0425} \\
\hline & $\mathbf{G}$ & 57,28 & 103,67 & 98,66 & 99,87 & & \\
\hline & B & 81,74 & 99,85 & 78,11 & 86,56 & & \\
\hline \multirow{3}{*}{ ڤ̊ำ } & $\mathbf{R}$ & 107,57 & 85,94 & 101,93 & 98,48 & \multirow{3}{*}{$-0,112$} & \multirow{3}{*}{0,0088} \\
\hline & $\mathbf{G}$ & 91,71 & 72,66 & 92,76 & 85,71 & & \\
\hline & B & 77,96 & 53,55 & 80,56 & 70,69 & & \\
\hline \multirow{3}{*}{ 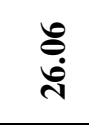 } & $\mathbf{R}$ & 103,45 & 104,17 & 129,48 & 112,36 & \multirow{3}{*}{$-0,153$} & \multirow{3}{*}{$-0,0309$} \\
\hline & $\mathbf{G}$ & 90,95 & 87,3 & 102,67 & 93,64 & & \\
\hline & B & 78,22 & 85,26 & 88,16 & 83,88 & & \\
\hline \multirow{3}{*}{$\begin{array}{l}\dot{0} \\
\dot{d} \\
\dot{d}\end{array}$} & $\mathbf{R}$ & - & 133,92 & - & - & \multirow{3}{*}{$-0,198$} & \multirow{3}{*}{$-0,044$} \\
\hline & $\mathbf{G}$ & - & 107,4 & - & - & & \\
\hline & $\mathbf{B}$ & - & 89,4 & - & - & & \\
\hline
\end{tabular}

The chart of the VARIgreen and ExG vegetation indices from the one-month observation shows that they became close to zero and negative at the end of June, as all values for the red light reflection are higher than those for the green light reflection. This was explained by the hours at which the measurement was taken. It was only three times a day at: 9.00; 12.00 and 15.00, when the intensity of sunshine, especially during the second and third measurements was highest for the day and due to the presence of many weeds with red flowers. 


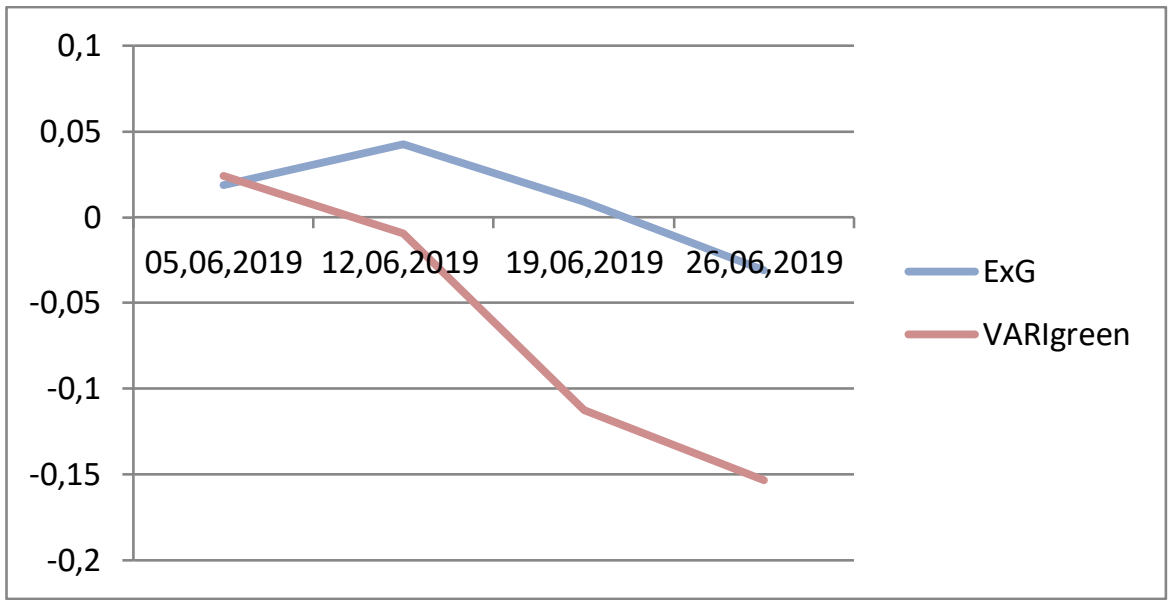

Fig. 2. Change of indices: VARIgreen and ExG within three months.

To reduce the atmospheric effects of the concept of ARVI (Atmospheric Resistance Vegetation Index), a VIgreen (Vegetation Index) was created. It is sensitive to green vegetation. The effect of the atmosphere on the red and green reflections was similar, as both were adjacent to the wavelength spectrum. Although green has a shorter wavelength, the green reflection is more intense, so the two effects were mutually neutralized. In the denominator of VIgreen, the atmospheric effects exist as green and red. In the VARI (Visible Atmospheric Resistance Index) it is assumed that the effect in blue is twice as large as in red so that for the correction of the effect of red and green the blue was subtracted. Thus, the VIgreen index was transformed into the following visible VARIgreen atmospheric resistance index, formula (1), (Gitelson, et al. 2002).

For the specific measurements from the RGB reflected light data obtained, the formulas for the indices were as follows: VARIgreen - Visible Atmospheric Resistance Index green:

$$
\text { VARIgreen }=\frac{R_{\text {Green }}-R_{\text {Red }}}{R_{\text {Green }}+R_{\text {Red }}-R_{\text {Blue }}}
$$

ExG - Excess Green Index, (Woebbeke et al. 1995):

$$
E x G=2 g-r-b
$$

where

$$
g=\frac{R_{\text {Green }}}{R_{\text {Green }}+R_{\text {Red }}+R_{\text {Blue }}} ; r=\frac{R_{\text {Red }}}{R_{\text {Green }}+R_{\text {Red }}+R_{\text {Blue }}} ; b=\frac{R_{\text {Blue }}}{R_{\text {Green }}+R_{\text {Red }}+R_{\text {Blue }}}
$$

The results of the complete factor experiment, (Митков, A., 2011) obtained using the SPSS software product were as follows: Piarson correlation between the dependent variables was verified. In this case they are the digitized values for the three colors with a combination of the factors: humidity, cloudiness and sunshine, (Table 2). Apparently, the computed correlation coefficients: red-green -0.251, red-blue 0.09 and blue-green 0.548 were insignificant, i.e. these correlations do not play a significant role during the experiment. 
Table 2. Pierson correlation

\begin{tabular}{|c|l|r|r|r|}
\hline \multicolumn{5}{|c|}{ Correlations } \\
\hline \multicolumn{2}{|c|}{ Variables } & \multicolumn{3}{c|}{ Variables } \\
\cline { 3 - 5 } & & \multicolumn{1}{|c|}{ Red } & Green & \multicolumn{1}{c|}{ Blue } \\
\hline \multirow{2}{*}{ Red } & Pearson Correlation & 1 & $-0,251$ & 0,099 \\
\cline { 2 - 5 } & Sig. (2-tailed) & & 0,550 & 0,8158 \\
\hline \multirow{2}{*}{ Green } & Pearson Correlation & - & 1 & 0,548 \\
& & 0,251 & & 0,160 \\
\cline { 2 - 5 } & Sig. (2-tailed) & 0,550 & & 1 \\
\hline \multirow{2}{*}{ Blue } & Pearson Correlation & 0,099 & 0,548 & 0,160 \\
\cline { 2 - 5 } & Sig. (2-tailed) & 0,815 & & 0 \\
\hline
\end{tabular}

Table 3. Experimental data from the complete factor experiment conducted and values of the vegetation indices.

\begin{tabular}{|c|c|c|c|c|c|c|c|c|}
\hline \multirow{2}{*}{$\begin{array}{c}\text { № } \\
\text { of ex- } \\
\text { peri- } \\
\text { ment }\end{array}$} & \multicolumn{3}{|c|}{ Atmospheric conditions (factors) } & \multicolumn{3}{|c|}{ Reflection / wavelength } & \multirow[b]{2}{*}{$\begin{array}{l}\text { VARI } \\
\text { green }\end{array}$} & \multirow[b]{2}{*}{ ExG } \\
\hline & $\begin{array}{c}\text { Humidity* } \\
\text { x1, } \varphi \%\end{array}$ & $\begin{array}{c}\text { Cloudiness } * \\
\mathbf{x}_{2}, \psi \%\end{array}$ & $\begin{array}{c}\text { Sunshine } \\
x_{3}, \Phi\left[W / \mathbf{m}^{2}\right]\end{array}$ & $\begin{array}{c}\text { Red } \\
630-685 \\
\mathbf{y}_{1},[\mathrm{~nm}] \\
\end{array}$ & $\begin{array}{c}\text { Green } \\
520-590 \\
\mathbf{y}_{2},[\mathrm{~nm}]\end{array}$ & $\begin{array}{c}\text { Blue } \\
440-510 \\
\text { y3, }[\mathrm{nm}]\end{array}$ & & \\
\hline 1 & 83 & 35 & 289 & 92,83 & 98,66 & 78,11 & 0,30 & 0,27 \\
\hline 2 & 75 & 25 & 763,55 & 93,19 & $\begin{array}{l}104,9 \\
3\end{array}$ & 92,08 & 0,38 & 0,26 \\
\hline 3 & 66 & 15 & 994,7 & 99,02 & 96,71 & 82,54 & 0,24 & 0,22 \\
\hline 4 & 57 & 6 & 1125 & 99,05 & 95,17 & 86,59 & 0,24 & 0,19 \\
\hline 5 & 55 & 9 & 1714,5 & 99,12 & $\begin{array}{l}103,6 \\
7\end{array}$ & 99,85 & 0,33 & 0,20 \\
\hline 6 & 50 & 36 & 1155,5 & 101,20 & 91,93 & 90,86 & 0,20 & 0,14 \\
\hline 7 & 46 & 42 & 824,2 & 103,93 & $\begin{array}{l}103,2 \\
3\end{array}$ & $\begin{array}{l}103,4 \\
4\end{array}$ & 0,29 & 0,16 \\
\hline 8 & 46 & 42 & 242,5 & 110,94 & 97,28 & 81,74 & 0,14 & 0,18 \\
\hline
\end{tabular}

* The humidity and cloud data were taken from the daily weather newsletter for the city of Dobrich, which was published on the Internet.

The regression analysis for the first variable y1 (reflected red light, Table 3) shows that the factors and the combination of them were insignificant: humidity, humidity-cloudiness and cloudiness-sunshine; for the second variable y2 (reflected green light), respectively: humidity-cloudiness, humiditysunshine and humidity-cloudiness-sunshine, and for the third variable y3 (reflected blue light), respectively: humidity-cloudiness, humidity-sunshine and humidity-cloudiness-sunshine.

The corrected models, which include the significant factors and combinations of them, are the following:

$$
\begin{aligned}
& Y_{\text {red }}=-0,54 x_{2}-0,78 x_{3}+0,28 x_{1} x_{3}-0,19 x_{1} x_{2} x_{3} \\
& Y_{\text {green }}=-0,65 x_{1}-0,38 x_{2}+0,39 x_{3}+0,48 x_{2} x_{3} \\
& Y_{\text {blue }}=-0,73 x_{1}-0,19 x_{2}+0,54 x_{1} x_{2}-0,34 x_{1} x_{2} x_{3}
\end{aligned}
$$

The correlation coefficient $\mathbf{R}^{2}$, after removing the insignificant factors, changed slightly and remained close to one. For the respective variables it was: for $\mathbf{y}_{\mathbf{1}} \mathbf{R}^{2}=0.961$; for $\mathbf{y}_{\mathbf{2}} \mathbf{R}^{2}=0.957$ and for $\mathbf{y}_{\mathbf{3}}$ $\mathbf{R}^{2}=0.981$.

The vegetation indices were calculated for the specific measurements from the data obtained for the RGB reflected light from the one-day observation. Figure 3 shows their change between 8.00 and 15.00, where "trial number" means measurement in the corresponding hour. From them it was seen that in the first hours of the day the indices were positive, and then they became negative. 


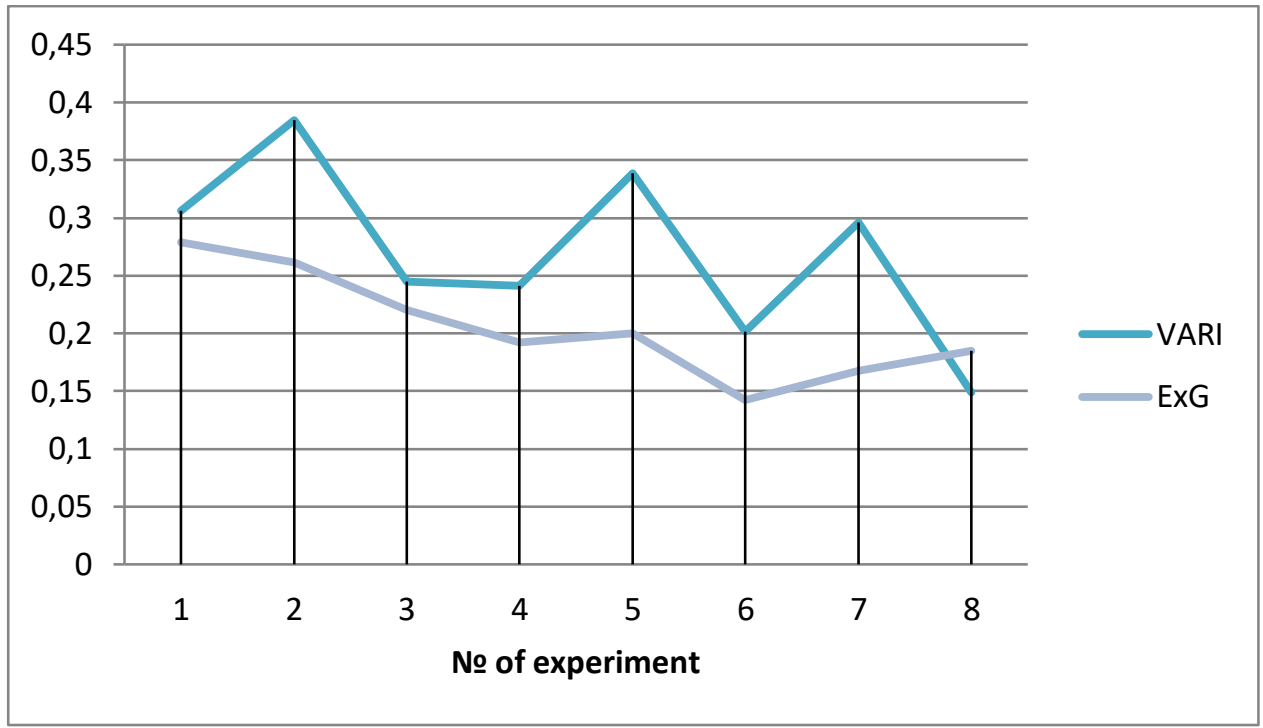

Fig. 3. Change of VARIgreen and ExG indices in one day.

During the day, they tended to decrease, due to the higher value of the reflected red light. Cloudiness and sunshine had an effect on this trend (See Table 2, Experiments 6, 7, and 8!), where it could be seen that the cloudiness increase and the sunshine decreases.

\section{CONCLUSIONS}

Digitized information was collected on the condition of an experimental field sown with six varieties of wheat. The analysis from the point of view of the condition of the different varieties of wheat through the indices VARIgreen and ExG from the images obtained with the RGB camera showed that all three indices tended to decrease during the day from 8.00 to 15.00. The times when it was most appropriate to shoot are: $11.00 ; 12.00$ and 13.00 . This is the time of day when the sun is near and at its zenith. Therefore, the recordings from Experiments 4 to 6 are of utmost importance (they are marked in Table 3 ). Then the three indexes follow a slightly downward trend.

Through a complete factor experiment of type $2^{3}$, it was determined which of the factors: humidity, cloudiness, sunshine and combinations of them were significant. After removing the insignificant factors the coefficient of certainty $\mathbf{R}^{2}$ decreased slightly.

\section{REFERENCES}

Бисерков, В., (2017), Нови технологични възможности за екосистемни анализи в България, cn. „Наука“, кн. 5, том XXXVII, изд. Съюз на учените в България, стр. 16- 22. ISBN 08613362.

Митков, А., (2011), Теория на експеримента, изд. „Дунавпрес“, Русе;

Chamurliyski, P., 2019. Historical aspects and achievements of the bread wheat (Triticum aestivum L.) in Southern Dobrudzha, New Knowledge Journal of Science, 8 (2): 60-70

Ekielski A., Koronczok J., Lorencki J., Czech T., \& Tulska E., (2017), Crops diagnosis using Hurst exponent values in field image analysis, DOI: 10.24326/fmtmsa.2017.19, 101-108;

Gitelson, A. A., Kaufman Y. J., Yoram J.; Stark Robert, \& Rundquist, D., (2002), Novel Algorithms for Remote Estimation of Vegetation, Fraction, Papers in Natural Resources. 149. http://digitalcommons.unl.edu/natrespapers/149;

Jackson R. D. (1983), Spectral Indices in n-Space, Pemote sensing of environment no. 13:409-421, 
Laliberte, A. S., \& Rango A., (2009), Texture and Scale in Object-Based Analysis of Subdecimeter Resolution Unmanned Aerial Vehicle (UAV) Imagery, IEEE transactions on geoscience and remote sensing, vol. 47, no. 3, march 2009;

Rao Mogili U. M., \& Deepak B. B. V. L, (2018), Review of application of drone system in precision agriculture, Procedia Computer Science 133 502-509;

Torres-Sanches J., Pena Baragan J. M., Gome-Candom D., De Castro A. I., \& Lopes Granados F., (2012) Imagery from unmanned aerial vehicle for early site specific weed management, Precision agricultures'13, 193199;

Van der Wal T., Abma B., Viguria A., Previnaire E., Zarco-Tejada P. J., Serruys P., van Valkengoed E., \& van der voet P., (2013), Field copter: unmanned aerial system for crop monitoring services, Precision agricultures'13, 169-175;

Woebbecke DM, Meyer GE, Von Bargen K, \& Mortensen DA. (1995), Color indices for weed identification under various soil, residue, and lighting conditions. Trans. Am. Soc. Agric. Eng., 38: 259-269.

\section{Online sources}

SPSS for Widows, "free software", (Date of Access 2019, June 25), Retrieved from https://spss.en.softonic.com/ 